\title{
Factors associated with diabetic foot among type 2 diabetes in Northern area of Saudi Arabia: a descriptive study
}

\author{
Manal S. Fawzy ${ }^{1,5^{*}}$, Mariam A. Alshammari ${ }^{2}$, Ashwaq A. Alruwaili², Rehab T. R. Alanazi ${ }^{2}$, Jewaher A. M. Alharbi ${ }^{2}$, \\ Abdulaziz Mohammed R. Almasoud ${ }^{2}$, Reem A. Alshammari ${ }^{3,4}$ and Eman A. Toraih ${ }^{6}$
}

\begin{abstract}
Objective: Foot complications are considered to be a devastating consequence of type 2 diabetes mellitus (T2DM), posing a major medical and economic burden. A prospective study was conducted at researchers' area "Northern area of Saudi Arabia" to determine the factors associated with diabetic foot (DF) among T2DM patients. Identifying the extent of this problem and the associated factors will enable the health providers to imply early preventive measurements.

Results: Two hundred T2DM patients with/without DF ( $n=100$ for each group) were recruited. In total, the mean (SD) age of participants was 56 ( \pm 12.2 ) years and nearly $70 \%$ of the patients were females. They showed a trend for higher frequency of impaired vibration perception, light touch pressure, proprioception and pain sensation than males in T2DM with DF. In univariate analysis, older age, long duration of diabetes and poor glycemic control reflected in high levels of $\mathrm{HbA} 1 \mathrm{c}$ were significant factors associated with $\mathrm{DF}(\mathrm{OR}=4.1,95 \% \mathrm{Cl} 2.3-7.4, P<0.0001 ; \mathrm{OR}=6.5,95 \%$ $\mathrm{Cl}(4.9-9.3), P<0.0001$, and $\mathrm{OR}=1.1,95 \% \mathrm{Cl}(1.05-1.3), P=0.002$, respectively). Taken together, the current results could highlight the importance of epidemiological studies to raise the awareness of this important health care problem around the country.
\end{abstract}

Keywords: Diabetic foot, Risk factors, Northern Borders area, Saudi Arabia

\section{Introduction}

Saudi Arabia is one of the top ten countries (the 6th rank) for diabetes prevalence and it is speculated to continue with a prevalence rate of $20.0 \%$ in the age group 20-79 years in the coming two decades [1]. The diabetic foot is characterized by a classical triad of neuropathy, ischemia, and infection and no wonder is one of the most serious complications of diabetes [2]. Diabetic foot ulcers are common and estimated to affect $15 \%$ of all diabetic individuals during their lifetime and is now appreciated that $15-20 \%$ of patients with such foot ulcers go on to need an amputation [3].

\footnotetext{
*Correspondence: manal2_khashana@ymail.com;

manal.darwish@nbu.edu.sa

${ }^{1}$ Department of Biochemistry, Faculty of Medicine, Northern Border

University, P.O. Box: 1321, Arar, Saudi Arabia

Full list of author information is available at the end of the article
}

Diabetes-related lower-extremity amputations rates are important indicators for the effectiveness of health care provided to diabetic patients including prevention and management of foot ulcers and to forecast the magnitude of the problem [4]. Previous studies have reported that early identification of people at high risk for foot problems and management of the risk factors could prevent lower extremity amputations and foot ulcerations $[5,6]$. To this end, identifying the role of risk factors for diabetic foot ulceration will enable health providers to implement better prevention programs that could result in improved patient quality of life and, thus, reduce the economic burden for both the patient and the health care system [7]. Hence, the findings of the present study could help diabetologists recognize early, and manage diabetic foot, and thus reduce the limb amputation risk, and the cost that accompanies limb loss in this prevalent condition.

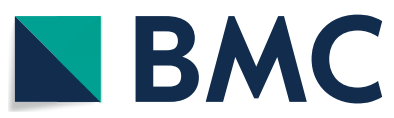

C The Author(s) 2019. This article is distributed under the terms of the Creative Commons Attribution 4.0 International License (http://creativecommons.org/licenses/by/4.0/), which permits unrestricted use, distribution, and reproduction in any medium, provided you give appropriate credit to the original author(s) and the source, provide a link to the Creative Commons license, and indicate if changes were made. The Creative Commons Public Domain Dedication waiver (http://creativecommons.org/ publicdomain/zero/1.0/) applies to the data made available in this article, unless otherwise stated. 


\section{Main text}

\section{Ethical considerations}

The study was conducted in accordance with the ethical standards of the institutional and national research committee and with the Helsinki Declaration and its later amendments. It was approved by the Medical and Bioethics local committee of Northern Border University. Participants were informed about the purpose of the study and data were collected after obtaining written consent from each patient. They were allowed to refuse or discontinue the participation at any time at request. Information was recorded anonymously and confidentiality and beneficence were assured throughout the study.

\section{Methods}

A facility based matched prospective case-control study was conducted to collect data from a total of 200 consecutive Saudi T2DM patients (with/without DF; $n=100$ for each group) presented during their routine visit to the diabetic center at the public Prince Hospital, Arar, Saudi Arabia from April 2018 up to May 2018. Data were collected using (1) interviewer administered structured questionnaire which was administered by the medical students for each diabetic patient and adopted by the local hospital protocols for diabetic foot, including the patient age, history of smoking, duration of DM, presence of hypertension and the current medication use, (2) observational and (3) chart analysis. The questioner reliability was previously checked by the hospital medical staff using coefficient alpha.

Body mass index [BMI; weight $(\mathrm{kg})$ divided by height (m) squared $\left(\mathrm{kg} / \mathrm{m}^{2}\right)$ ] and blood pressure (measured by an electronic vital signs monitor (SureSigns VS3, Philips Medical System, MA, USA) have been measured.

Permission was taken from the hospital administration to allow the researchers to revise the patients' medical records archived in a specified diabetic center system (Medical plus). The nature of diabetic foot lesion and complications (i.e. ulcer, gangrene or amputation) [8], peripheral vascular pulses [9] and peripheral neurological status $[10,11]$, were retrieved from patients' medical records. Diabetes glycemic parameters namely; fasting blood glucose (FBG; mmol/l) and hemoglobin A1c (HbA1c \%) levels were collected from patients' laboratory data according to their latest hospital visit.

\section{Statistical analysis}

Data analyses were conducted using Statistical Package for the Social Sciences (SPSS) software version 23 (IBM SPSS Inc, Chicago, IL, USA). Shapiro-Wilk test and Levene test were applied for data distribution and variance homogeneity check, respectively. Sample size of the study was calculated using G power software (http:// www.gpower.hhu.de). Calculations showed that with the specified study design (case-control), and allowable error rates; alpha error $=0.5$ with sample size 100 for each group can give $94 \%$ power with an effect size $=0.5$. All the categorical variables were presented as number (percentage) and compared by Chi square $\left(\chi^{2}\right)$ or Fisher's exact tests where appropriate. All the continuous variables were presented as mean \pm standard deviation and the Student' $\mathrm{s}$ t test was used for sub-group comparison. Univariate analysis was performed to identify factors associated with DF among T2DM. Bivariate correlation matrix using Spearman's rank correlation analysis was applied to correlate between different parameters of the study. Multivariate analysis using the principal component analysis for data exploration was run to test the possibility of patients clustering according to the study variables. Significance was set at $P<0.05$.

\section{Results}

\section{Baseline characteristics of the study population}

Patients' baseline characteristics are shown in Table 1 and Fig. 1a. The T2DM female patients were more prevalent in both studied groups. The mean age of participants, mean BMI, presence of obesity and current smoking status were similar in both T2DM with/without DF. Univariate analysis showed that higher frequency of older age, longer mean duration of diabetes, and higher mean HbA1c (\%) levels were evident in T2DM with DF [OR (95\% CI): 4.1 (2.3-7.4), 6.5 (4.9-9.3), 1.1 (1.05-1.3), respectively].

Compared to male participants, female patients had higher values of BMI in T2DM with/without DF $(P=0.010$ and 0.061 , respectively), but with negative history of smoking. Primary hypertension was reported in $40 \%$ and $59 \%$ of the patients with/without DF, respectively. Most of T2DM patients with DF (76\%) were taking oral hypoglycemic drugs only or with insulin (7\%). Around half (45\%) of them had diabetes more than 10 years; $31 \%$ were of duration between 10 and 20 years, $12 \%$ and $2 \%$ were of duration more than 20 and 30 years, respectively, whereas $31 \%$ were of duration between 5-10 years and only 6 patients were newly diagnosed. The proportion of male and female patients with different durations of diabetes mellitus among T2DM with DF has illustrated in Fig. 1b. As an overall trend, more men had prolonged disease span $\geq 25$ years long compared to women, unlike other age categories $(P=0.091)$. As can be seen, large sector of females experienced the disease from 5 to 15 years, whereas, high frequency of males were categorized either at the disease duration between 5 and 10 or $\geq 25$ years. 
Table 1 Baseline characteristics of study population

\begin{tabular}{|c|c|c|c|c|c|c|c|c|c|c|}
\hline & \multicolumn{4}{|c|}{ T2DM patients } & \multicolumn{4}{|c|}{ T2DM patients with foot ulcer } & \multirow[t]{2}{*}{$P$ value $^{a}$} & \multirow[t]{2}{*}{ OR $(95 \% \mathrm{Cl})$} \\
\hline & Total & Female & Male & $P$ value & Total & Female & Male & $P$ value & & \\
\hline Total number & 100 & 71 & 29 & & 100 & 72 & 28 & & & \\
\hline Age (years) & $56.4 \pm 12.2$ & $55.9 \pm 11.8$ & $57.1 \pm 13.2$ & 0.638 & $56.7 \pm 12.2$ & $56.5 \pm 11.7$ & $57.1 \pm 13.4$ & 0.798 & 0.862 & \\
\hline \multicolumn{11}{|l|}{ Age categories (years) } \\
\hline$\leq 50$ & $66(66.0)$ & $48(67.6)$ & $18(62.1)$ & 0.080 & $32(32.0)$ & $23(31.9)$ & $9(32.1)$ & 0.985 & $<0.0001$ & $4.1(2.3-7.4)$ \\
\hline$>50$ & $34(34.0)$ & $23(32.4)$ & $11(37.9)$ & & $68(68.0)$ & $49(68.1)$ & $19(67.9)$ & & & \\
\hline \multicolumn{11}{|l|}{ Body mass index } \\
\hline$\left(\mathrm{Kg} / \mathrm{m}^{2}\right)$ & $31.0 \pm 6.1$ & $31.8 \pm 6.7$ & $28.3 \pm 4.0$ & 0.010 & $30.0 \pm 6.2$ & $30.8 \pm 6.9$ & $28.1 \pm 3.9$ & 0.061 & 0.251 & \\
\hline DM duration (years) & $13.4 \pm 7.9$ & $13.7 \pm 6.4$ & $13.2 \pm 9.2$ & 0.757 & $20.5 \pm 7.6$ & $19.9 \pm 6.8$ & $20.2 \pm 9.1$ & 0.857 & $<0.0001$ & $6.5(4.9-9.3)$ \\
\hline \multicolumn{11}{|l|}{ Obesity } \\
\hline Negative & $68(68.0)$ & $48(67.7)$ & $20(69.0)$ & 0.894 & $59(59.0)$ & $39(54.2)$ & $20(71.4)$ & 0.174 & 0.187 & $1.5(0.8-2.6)$ \\
\hline Positive & $32(32.0)$ & $23(32.3)$ & $9(31.0)$ & & $41(41.0)$ & $33(45.8)$ & $8(28.6)$ & & & \\
\hline \multicolumn{11}{|l|}{ Smoking } \\
\hline Negative & $89(89.0)$ & $71(100)$ & $18(62.1)$ & $<0.001$ & $94(94.0)$ & $72(100)$ & $22(78.6)$ & $<0.001$ & 0.211 & $0.5(0.2-1.5)$ \\
\hline Positive & $11(11.0)$ & $0(0.0)$ & $11(37.9)$ & & $6(6.0)$ & $0(0.0)$ & $6(21.4)$ & & & \\
\hline \multicolumn{11}{|l|}{ Hypertension } \\
\hline Negative & $41(41.0)$ & $23(32.3)$ & $18(62.1)$ & 0.006 & $60(60.0)$ & $41(56.9)$ & 19 (67.9) & 0.369 & 0.007 & $0.5(0 .-0.8)$ \\
\hline Positive & $59(59.0)$ & $48(67.7)$ & $11(37.9)$ & & $40(40.0)$ & $31(43.1)$ & $9(32.1)$ & & & \\
\hline $\mathrm{FBG}(\mathrm{mmol} / \mathrm{l})$ & $9.0 \pm 1.0$ & $9.4 \pm 0.9$ & $8.7 \pm 0.7$ & $<0.001$ & $9.2 \pm 2.9$ & $9.4 \pm 3.0$ & $8.51 \pm 2.7$ & 0.159 & 0.515 & \\
\hline HbA1c (\%) & $8.0 \pm 0.4$ & $8.3 \pm 0.5$ & $7.9 \pm 0.2$ & $<0.001$ & $8.5 \pm 1.5$ & $8.5 \pm 1.4$ & $8.6 \pm 1.7$ & 0.653 & 0.002 & $1.1(1.05-1.3)$ \\
\hline
\end{tabular}

Data are shown as mean \pm SD or number (percentage). Obesity (positive) a body mass index of 30 kilograms divided by height in meters squared (kg/ ${ }^{2}$ ) or above, Hypertension (positive) history of treated hypertension or blood pressure $\geq 140 / 90 \mathrm{mmHg}$, FBG fasting blood glucose, HbA1c Glycated hemoglobin, OR $95 \%$ Cl Odds ratio $95 \%$ confidence interval. ${ }^{a} P$ value was calculated using total T2DM with and without DF. Student's t and Chi square/Fisher's exact tests were used for comparison. Italic values indicate significance at $P<0.05$

\section{Characteristics of diabetic foot among T2DM with DF}

All patients except one female patient with amputation below the knee had a single ulcer disease. Lesions in less than three quarters were in the left foot, and most ulcers were in the forefoot region. Local examination showed dryness and fissured skin with fungal infection (3\%), claw toe deformity (2\%) or hammer toe (1\%). All patients had intact ankle reflex and most of them had intact sensation. Diabetic foot patients received mainly treatment for the infection and pressure offloading. Although stratification analysis by sex revealed that more trend of higher frequency of impaired vibration perception, light touch pressure, proprioception and pain sensation prevalent in females than males (Fig. 1c-f), these trends were not significant. Multivariate analysis by principal component analysis for data exploration revealed unclear demarcation between patients of different sex and regarding obesity (Fig. 1g, h). The bivariate correlation matrix showed significant correlations between duration of disease and several diabetic foot manifestations like impaired vibration perception, pressure sensation by monofilament test, and impaired position sensation albeit they were weak correlations ( $r=0.20,0.21$, and 0.22 , respectively).

\section{Biochemical analysis}

Large percentage of patients $(89 \%)$ had poor glycemic control $(\mathrm{HbA} 1 \mathrm{c} \geq 7.0 \%)$ with (mean $\pm \mathrm{SD}) ; 8.5 \pm 1.5$ and $8.0 \pm 0.4 \%$ in T2DM with/without DF, respectively. Female patients presented with higher levels of mean FBG and HbA1c levels than males in T2DM without DF $(P<0.001)$.

(See figure on next page.)

Fig. 1 Clinical characteristics of diabetic foot ulcer patients. $\mathbf{a}, \mathbf{b}$ Frequency of males and female patients according to their age group and duration of diabetes disease. c-f Frequency of some clinical features of T2DM with foot ulcer. $\mathbf{g}$, h Multivariate analysis using Principal Component Analysis. Results were plotted on both axes and stratification was done by gender $(\mathbf{g})$ and obesity $(\mathbf{h})$. i Bivariate correlation matrix using Spearman's rank correlation analysis, only significant values are shown. Chi square/Fisher's exact tests were used for comparison between frequencies. Dim dimension, BMI body mass index, HbAlc glycated hemoglobin, FBS fasting blood sugar, HTN hypertension 


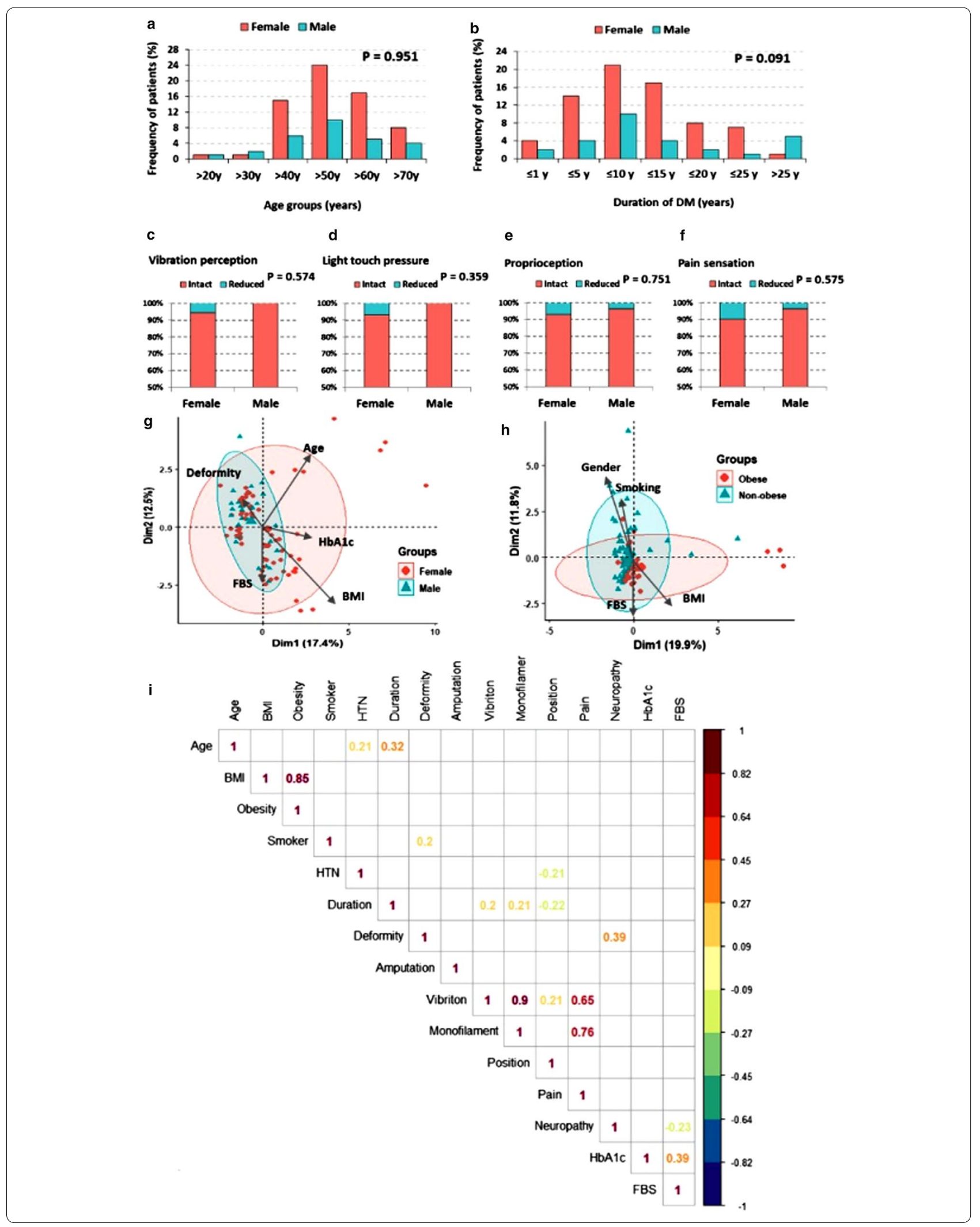




\section{Discussion}

In light of the great burden of T2DM and its complications including the DF disease in Saudi Arabia where disease prevalence ranges from 11.4 to $29.7 \%$ [12, 13], the current study was conducted to identify the factors associated with DF in the researchers' area "Northern Borders of Saudi Arabia". DF disease is one of the major health problems that impairs the patient's quality of life, entails high cost, and requires prolonged hospitalization [14]. Furthermore, most amputations begin with ulcers and can be prevented by good foot care and screening to assess the risk of foot complications [15].

The mean age of the study participants was about $56( \pm 12.2)$ years with about $68 \%$ of them aged above 50 years. In univariate analysis, older age was associated with higher frequency of diabetic foot occurrence. This finding was comparable with Al-Rubeaan et al. [7] in their retrospective cohort study where they reported that "age $\geq 45$ years is a risk factor for developing diabetic foot ulcers in Saudi population". Similarly, in the study about the factors associated with amputation among DF ulcer patients in Saudi population, Musa and his colleagues [16], recently highlighted the "epidemic of metabolic syndrome around the world", which particularly affects the Gulf region, being responsible for a younger age at the onset of the disease.

Contrary to the findings of some studies that found that male sex was predominant in DF patients $[9,17]$, female patients in the current T2DM cohorts were more prevalent. The influence of sex on DF disease was controversial [18]. Dinah and Vives found in their multicenter analysis, which included 248 T2DM patients with DF, that sex may imply a significant risk factor for the development of diabetic ulcers [19]. They argued that females could have a lower risk relative to males partly because of less severe neuropathy, increased joint movement, and lower foot pressure. However, once neuropathy or other risk factors for DF are present, both sexes have equal risk of DF development. The authors cannot exclude the impact of gender norms on women's health in the local area. According to Aldosari [20], "women may find that health services are inaccessible or conditioned on certain cultural grounds or gender norms, such as restrictions imposed by the male guardianship system, women's driving ban, gender segregation and religious norms affect access, quality and outcomes for women in Saudi Arabia". These factors can also contribute to the more trend of higher frequency of DF-related manifestations observed in the current female patients than males. Large-scale studies are warranted to validate this issue.

The current study revealed that $41 \%$ and $32 \%$ of T2DM with/without DF were generally obese. Despite a number of studies shows a correlation between increased body weight and increased risk of foot ulcers [21, 22], due to a speculated effect of body weight on planter pressure, however, such correlation was not consistent [23].

Our univariate analysis also revealed that the duration of diabetes was a major contributory factor to the increased incidence of DF disorders (nearly by 6.5 -fold). This finding was in line with the previous studies that support the association between prevalence of DF and duration of diabetes [24-27]. Also, it is worth noting that DF disorders are common among diabetic patients even at the early stage of diabetes or at the time they were diagnosed as T2DM [28]. Although the duration of diabetes is not a modifiable risk factor, it is of great importance for early identification and management of DF disorders as stated by Alzahrani et al. [9].

Higher frequency of the study patients $(89 \%)$ were reported to have poor glycemic control that showed significant association with DF development. This finding was consistent with other studies that reported poor glycemic control as one of the main factors implicated in DF problems [29, 30]. Previous studies have also shown that HbA1c was a contributory factor for DF ulcer [19, 31, 32]. This may be due to hyperglycemia, which has been considered a risk factor for the development of DF ulcers because of its contribution toward the development of peripheral neuropathy and microvascular complications [25].

Taken together, this study identified that the older age, disease duration and poor glycemic control are significant risk factors related to DF development in the current T2DM population. Most of these factors are correctable or at least controllable with a large opportunity for early prevention and treatment, with the subsequent reduction in patients with DF and its devastating sequel of amputation.

\section{Limitations}

- This study is quantitative; it was better if qualitative approach was also employed, which is recommended in the future studies.

- The adjustment for the other potential major contributing factors and other diabetic microangiopathic complications was not carried out in the current study.

- The authors did not consider some potential confounders in the occurrence of new foot ulceration such as health care provision level and patient behavioral factors like compliance with training on their foot care. 


\section{Abbreviations}

BMI: body mass index; DF: diabetic foot; FBG: fasting blood glucose; HbA1C: glycated hemoglobin; SPSS: Statistics Package for Social Science; T2DM: type 2 diabetes mellitus.

\section{Authors' contributions}

MSF, MAA, AAA, RTRA, JAMA, AMRA and RAA conceptualized and designed the study. MAA, AAA, RTA, JAA, MMJ, AMRA and RAA conducted data collection and wrote the initial report. EAT data acquisition and analysis for the control group, and execution of the statistical analysis, MSF supervised the work, carried out the initial analysis, drafted, reviewed, and revised the manuscript, and approved the final manuscript as submitted. All authors read and approved the final manuscript.

\section{Author details}

${ }^{1}$ Department of Biochemistry, Faculty of Medicine, Northern Border University, P.O. Box: 1321, Arar, Saudi Arabia. ${ }^{2}$ Faculty of Medicine, Northern Border University, Arar, Saudi Arabia. ${ }^{3}$ Faculty of Pharmacy, Northern Border University, Rafha, Saudi Arabia. ${ }^{4}$ Rafha Central Hospital, Rafha, Saudi Arabia. ${ }^{5}$ Department of Medical Biochemistry and Molecular Biology, Faculty of Medicine, Suez Canal University, Ismailia, Egypt. ${ }^{6}$ Genetics Unit, Department of Histology and Cell Biology, Faculty of Medicine, Suez Canal University, Ismailia, Egypt.

\section{Acknowledgements}

The authors would like to thank all the staff and the administrative authorities in the diabetic center at Prince Hospital, Arar, Saudi Arabia for their collaboration. Thanks extended to all the patients who agree to participate in the present study.

\section{Competing interests}

The authors declare that they have no competing interests.

\section{Availability of data and materials}

The data sets used and analyzed during the current study available from the corresponding author on reasonable request.

\section{Consent to publish}

Not applicable.

\section{Ethics approval and consent to participate}

Ethical clearance was obtained from the Medical and Bioethics local committee of Northern Border University. Informed consent has been taken from each participant.

\section{Funding}

None.

\section{Publisher's Note}

Springer Nature remains neutral with regard to jurisdictional claims in published maps and institutional affiliations.

Received: 11 December 2018 Accepted: 14 January 2019

Published online: 22 January 2019

\section{References}

1. Alqurashi KA, Aljabri KS, Bokhari SA. Prevalence of diabetes mellitus in a Saudi community. Ann Saudi Med. 2011;31(1):19-23.

2. Pendsey SP. Understanding diabetic foot. Int J Diabetes Dev Countries. 2010;30(2):75-9.

3. Yazdanpanah L, Nasiri M, Adarvishi S. Literature review on the management of diabetic foot ulcer. World J Diabetes. 2015;6(1):37-53.

4. Jeffcoate WJ, van Houtum WH. Amputation as a marker of the quality of foot care in diabetes. Diabetologia. 2004;47:2051-8.

5. Ogrin R, Sands A. Foot assessment in patients with diabetes Aust. Fam Physician. 2006;35:419-21.

6. Elsharawy MA, Hassan K, Alawad N, Kredees A, Almulhim A. Screening of diabetic foot in surgical inpatients: a hospital-based study in Saudi Arabia. Int J Angiol. 2012;21:213-6.
7. Al-Rubeaan K, Al Derwish M, Ouizi S, Youssef AM, Subhani SN, Ibrahim $\mathrm{HM}$, et al. Diabetic foot complications and their risk factors from a large retrospective cohort study. PLoS ONE. 2015;10:e0124446.

8. Oyibo SO, Jude EB, Tarawneh I, Nguyen HC, Harkless LB, Boulton AJ. A comparison of two diabetic foot ulcer classification systems: the Wagner and the University of Texas wound classification systems. Diabetes Care. 2001;24:84-8.

9. Alzahrani HA, Wang D, Alzahrani AH, Hu FB. Incidence of diabetic foot disorders in patients with diabetes in Jeddah, Saudi Arabia. Int J Diab Dev Countries. 2015;35:115-22.

10. Papanas N, Papatheodorou K, Papazoglou D, Monastiriotis C, Christakidis D, Maltezos E. A comparison of the new indicator test for sudomotor function (Neuropad) with the vibration perception threshold and the clinical examination in the diagnosis of peripheral neuropathy in subjects with type 2 diabetes. Exp Clin Endocrinol Diabetes. 2008; 116:135-8.

11. Craig AB, Strauss MB, Daniller A, Miller SS. Foot sensation testing in the patient with diabetes: introduction of the quick \& easy assessment tool. Wounds. 2014;26:221-31.

12. Hu Y, Bakhotmah BA, Alzahrani OH, Wang D, Hu FB, Alzahrani HA. Predictors of diabetes foot complications among patients with diabetes in Saudi Arabia. Diabetes Res Clin Pract. 2014;106:286-94.

13. Mairghani M, Elmusharaf K, Patton D, Burns J, Eltahir O, Jassim G, et al. The prevalence and incidence of diabetic foot ulcers among five countries in the Arab world: a systematic review. J Wound Care. 2017;26:S27-34.

14. Mauricio D, Jude E, Piaggesi A, Frykberg R. Diabetic foot: current status and future prospects. J Diabetes Res. 2016;2016:5691305.

15. Singh N, Armstrong DG, Lipsky BA. Preventing foot ulcers in patients with diabetes. JAMA. 2005;359:217-28.

16. Musa IR, Ahmed MON, Sabir El, Alsheneber IF, Ibrahim EME, Mohamed GB, et al. Factors associated with amputation among patients with diabetic foot ulcers in a Saudi population. BMC Res Notes. 2018;11:260.

17. Ribu L, Hanestad BR, Moum T, Birkeland K, Rustoen T. A comparison of the health-related quality of life in patients with diabetic foot ulcers, with a diabetes group and a nondiabetes group from the general population. Qual Life Res. 2007;16:179-89.

18. Peek ME. Gender Differences in Diabetes-related Lower Extremity Amputations. Clin Orthop Relat Res. 2011;469:1951-5.

19. Dinh T, Veves A. The influence of gender as a risk factor in diabetic foot ulceration. Wounds. 2008;20:127-31.

20. Aldosari $\mathrm{H}$. The effect of gender norms on women's health in Saudi Arabia. Arab Gulf States Institute in Washington; 2017. http://www.agsiw .org/effect-gender-norms-womens-health-saudi-arabia/ Accessed 20 Nov 2018.

21. Mantey I, Foster AV, Spencer S. Why do foot ulcers recur in diabetic patients? Diabet Med. 1999;16:245-9.

22. Boyko EJ, Ahroni JH, Stensel V. A prospective study of risk factors for diabetic foot ulcer. The Seattle Diabetic Foot Study. Diabetes Care. 1999;22:1036-42.

23. Cavanagh PR, Sims DS, Sanders LJ. Body mass is a poor predictor of peak plantar pressure in diabetic men. Diabetes Care. 1991;14:750-5.

24. Halawa MR, Karawagh A, Zeidan A, Mahmoud AE, Sakr M, Hegazy A. Prevalence of painful diabetic peripheral neuropathy among patients suffering from diabetes mellitus in Saudi Arabia. Curr Med Res Opin. 2010;26:337-43.

25. Al Kafrawy NA, Mustafa EA, Dawood ADA, Ebaid OM, Ahmed Zidane OM. Study of risk factors of diabetic foot ulcers. Menoufia Med J. 2014; 27:28-34. http://www.mmj.eg.net/text.asp?2014/27/1/28/132298. Accessed 9 Dec 2018.

26. Assaad-Khalil SH, Zaki A, Abdel Rehim A, Megallaa MH, Gaber N, Gamal H, et al. Prevalence of diabetic foot disorders and related risk factors among Egyptian subjects with diabetes. Prim Care Diabetes. 2015;9:297-303.

27. Almobarak AO, Awadalla H, Osman M, Ahmed MH. Prevalence of diabetic foot ulceration and associated risk factors: an old and still major public health problem in Khartoum, Sudan? Ann Transl Med. 2017;5:340.

28. New J, McDowell D, Burns E, Young R. Problem of amputations in patients with newly diagnosed diabetes mellitus. Diabet Med. 1998;15:760-4.

29. Nyamu PN, Otieno CF, Amayo EO, McLigeyo SO. Risk factors and prevalence of diabetic foot ulcers at Kenyatta National Hospital, Nairobi. East Afr Med J. 2003:80:36-43. 
30. Dubský M, Jirkovská A, Bem R, Fejfarová V, Skibová J, Schaper NC, et al. Risk factors for recurrence of diabetic foot ulcers: prospective follow-up analysis of a Eurodiale subgroup. Int Wound J. 2012;10:555-61.

31. Shahi SK, Kumar A, Kumar S, Singh SK, Gupta SK, Singh TB. Prevalence of diabetic foot ulcer and associated risk factors in diabetic patients from north India. J Diabet Foot Complications. 2012;4:83-91.
32. Lavery LA, Armstrong DG, Wunderlich RP, Mohler MJ, Wendel CS, Lipsky BA. Risk factors for foot infections in individuals with diabetes. Diabetes Care. 2006;29:1288-93.
Ready to submit your research? Choose BMC and benefit from:

- fast, convenient online submission

- thorough peer review by experienced researchers in your field

- rapid publication on acceptance

- support for research data, including large and complex data types

- gold Open Access which fosters wider collaboration and increased citations

- maximum visibility for your research: over 100M website views per year

At BMC, research is always in progress.

Learn more biomedcentral.com/submissions 